\title{
Projected 21st-century changes to Arctic marine access
}

\author{
Scott R. Stephenson • Laurence C. Smith • \\ Lawson W. Brigham • John A. Agnew
}

Received: 31 July 2012 / Accepted: 23 December 2012 /Published online: 24 January 2013

(C) The Author(s) 2013. This article is published with open access at Springerlink.com

\begin{abstract}
Climate models project continued Arctic sea ice reductions with nearly ice-free summer conditions by the mid-21st century. However, how such reductions will realistically enable marine access is not well understood, especially considering a range of climatic scenarios and ship types. We present 21 st century projections of technical shipping accessibility for circumpolar and national scales, the international high seas, and three potential navigation routes. Projections of marine access are based on monthly and daily CCSM4 sea ice concentration and thickness simulations for 2011-2030, 2046-2065, and 2080-2099 under $4.5,6.0$, and $8.5 \mathrm{~W} / \mathrm{m}^{2}$ radiative forcing scenarios. Results suggest substantial areas of the Arctic will become newly accessible to Polar Class 3, Polar Class 6, and open-water vessels, rising from $\sim 54 \%, 36 \%$, and $23 \%$, respectively of the circumpolar International Maritime Organization Guidelines Boundary area in the late 20th century to $\sim 95 \%, 78 \%$, and $49 \%$, respectively by the late 21 st century. Of the five Arctic Ocean coastal states, Russia experiences the greatest percentage access increases to its exclusive economic zone, followed by Greenland/Denmark, Norway, Canada and the U.S. Along the Northern Sea Route, July-October navigation season length averages $~ 120,113$, and 103 days for PC3, PC6, and OW vessels, respectively by late-century, with shorter seasons but substantial increases along the Northwest Passage and Trans-Polar Route. While Arctic navigation depends on other factors besides sea ice including economics, infrastructure, bathymetry, and weather, these projections are useful for strategic planning by governments, regulatory agencies, and the global maritime industry to assess spatial and temporal ranges of potential Arctic marine operations in the coming decades.
\end{abstract}

Electronic supplementary material The online version of this article (doi:10.1007/s10584-012-0685-0) contains supplementary material, which is available to authorized users.

S. R. Stephenson $(\bowtie) \cdot$ L. C. Smith $\cdot$ J. A. Agnew

Department of Geography, University of California, Los Angeles, CA 90095, USA

e-mail: stephenson@ucla.edu

L. C. Smith

Department of Earth \& Space Sciences, University of California, Los Angeles, CA 90095, USA

L. W. Brigham

UA Geography Program, University of Alaska Fairbanks, AK 99775, USA 


\section{Introduction}

Reduced Arctic sea ice continues to be a palpable signal of global change. Record lows in September sea ice extent in 2007 and 2012 underscore robust downward trends in ice extent and thickness observed since 1979 (Maslanik et al. 2007; Serreze et al. 2007; Comiso et al. 2008; Stroeve et al. 2008; Kwok et al. 2009; Stroeve et al. 2012a). Since the 1980s, the extent of older, thicker multiyear ice (MYI) has decreased $\sim 15 \%$ per decade, driven especially by reductions in March (declining from $\sim 75 \%$ to $45 \%$ ) and September ( $60 \%$ to $\sim 15 \%$ ) (Maslanik et al. 2011; Comiso 2012; Polyakov et al. 2012). Reductions have also occurred in winter, with circumpolar maximum ice extent falling to $\sim 614,000 \mathrm{~km}^{2}$ below the 1979-2000 mean in March 2012 (NSIDC 2012). While natural climatic variability has caused interannual fluctuations in sea ice extent throughout human history, the current decline is attributed primarily to anthropogenic greenhouse gas emissions (Kay et al. 2011; Day et al. 2012; Notz and Marotzke 2012) with a magnitude unprecedented over the past 1,450 years (Kinnard et al. 2011). Climate model simulations share universal agreement on continued ice reductions throughout the 21 st century (Zhang and Walsh 2006; Christensen et al. 2007; Wang and Overland 2009; Vavrus et al. 2012), though with some significant timing differences. A short period of ice-free conditions in summer has been projected as early as 2030 (Wang and Overland 2009) and as late as 2100 (Boe et al. 2009). Furthermore, recent satellite observations indicate that many climate model simulations underestimate the true rate of ice loss, perhaps due to observational uncertainties, vigorous climate variability, and gaps in understanding physical processes such as ice drift (Kattsov et al. 2010; Rampal et al. 2011).

Despite model uncertainties these simulations, together with over three decades of satellite observations, have spurred new economic interest in Arctic shipping and offshore natural resources (Astill 2012). Reduced ice extent - and lower MYI concentrations, in particular portend longer, more flexible navigation seasons in the region and increased viability of built structures such as drilling platforms (Arctic Council 2009). All five Arctic Ocean coastal states (Canada, Greenland/Denmark, Norway, Russia, U.S.) have been conducting mapping projects to extend the limit of their outer continental shelves under Article 76 of UNCLOS, the United Nations Convention on the Law of the Sea (Potts and Schofield 2008), while offshore oil and gas reserves are stimulating investment in the region (Barents Observer 2011a). Trans-Arctic routes linking major world oceans are receiving attention as a potential future alternative to the Suez and Panama Canals, encouraged in part by recent shipping milestones in the Northern Sea Route (NSR) (Barents Observer 2011b; Barents Observer 2011c).

Modeling studies of future Arctic maritime activity have typically presented results as a series of scenarios, with shipping potential defined in various ways including technically accessible area (Stephenson et al. 2011), transit time (Liu and Kronbak 2010; Peters et al. 2011; Stephenson et al. 2011), fuel consumption (Paxian et al. 2010; Peters et al. 2011), navigation season length (ACIA 2004a; Khon et al. 2010), and economic viability (Somanathan et al. 2007; Somanathan et al. 2009; Khon et al. 2010; Liu and Kronbak 2010). Here, a new approach combines projections of 21 st-century Arctic technically accessible area, navigation season length, and temporal variability to simulate marine access as a function of both climatic (ice) conditions and vessel class. Projections are based on sea ice simulations for three climatic forcing scenarios $\left(4.5,6.0\right.$, and $\left.8.5 \mathrm{~W} / \mathrm{m}^{2}\right)$ during the early (2011-2030), mid(2046-2065), and late-21st century (2080-2099); assuming Polar Class 3 (PC3), Polar Class 6 (PC6), and open-water vessels (OW) with high, medium, and no ice-breaking capability, respectively. Unlike previous studies, the prospect that future maritime use of the Arctic will have different modes and purposes is thus recognized with inclusion of OW vessels particularly important because they comprise the vast majority of the world fleet. Results are presented for 
the entire circumpolar region, the current exclusive economic zones (EEZs) of the five Arctic Ocean coastal states (Canada, Greenland/Denmark, Norway, Russia, U.S.), three potential shipping routes (Northwest Passage, Northern Sea Route, Trans-Polar Route), and the international high seas of the central Arctic Ocean.

\section{Methods}

\subsection{Study area}

The area of analysis covers approximately $14 \mathrm{Mkm}^{2}$ and consists of the entire Arctic marine environment circumscribed within the International Maritime Organization (IMO) Guidelines Boundary (IMO 2002) (Fig. 1). The IMO Guidelines Boundary is intended to delineate area

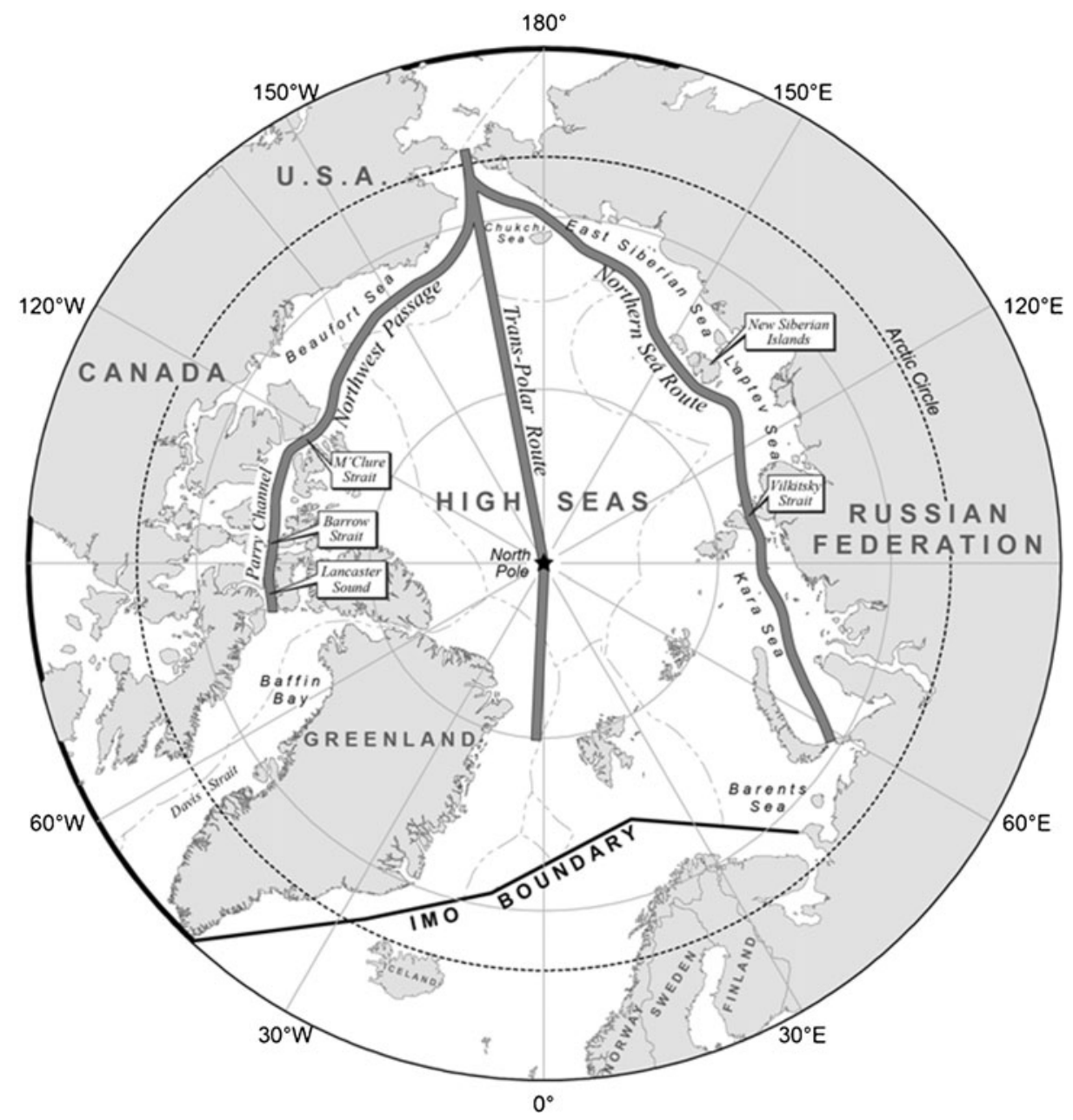

Fig. 1 Selected navigation routes used in this analysis (NWP, NSR, TPR), international high seas, and marine EEZs (dashed lines) of Canada, Greenland, Norway, Russia, and the U.S. within the IMO Arctic Ship Guidelines Boundary (thick black border) 
with potentially hazardous ice conditions necessitating ice-strengthened ships. This overall study area is further subdivided into five maritime exclusive economic zones (EEZ) of the Arctic Ocean coastal states (Canada, Greenland/Denmark, Norway, Russia, U.S.), defined as ocean beyond a state's territorial sea extending up to 200 nautical miles from its coast. The central Arctic Ocean beyond EEZ boundaries was defined as "international high seas." Unlike Stephenson et al. (2011), the present study considers only current EEZs, omitting potential future EEZ extensions to be potentially granted under UNCLOS Article 76. Three potential trans-Arctic navigation routes were also analyzed, namely the Northwest Passage (NWP), Northern Sea Route (NSR) and Trans-Polar route (TPR) (Fig. 1). The NWP was defined from the Baffin Bay mouth of Lancaster Sound westward through the Parry Channel and M'Clure Strait, turning southwest $100 \mathrm{~km}$ north of Point Barrow, Alaska, and terminating at the Bering Strait. The NSR was defined in accordance with Russian law as a coastal route running from Kara Gate south of Novaya Zemlya to the Bering Strait. The Trans-Polar route (TPR) was defined as a Great Circle route from the Fram Strait to the North Pole, followed by another Great Circle route to the Bering Strait. While the TPR is the only route crossing the pole, all three routes may be considered "transArctic" as they connect major world oceans. To account for minor navigation deviations, routes were represented as a $25-\mathrm{km}$ buffer around each route centerline (Fig. 1).

Complete study area definitions are provided in Supplementary Methods.

\subsection{Sea ice data}

Future sea-ice characteristics were obtained from ice concentration and thickness simulations from the Los Alamos sea ice model (CICE) component of CCSM4 (NCAR 2012) (see Supplementary Methods for model details). Data were obtained from the Coupled Model Intercomparison Project Phase 5 (CMIP5) archive. Three climate forcing scenarios were used from the forthcoming IPCC Fifth Assessment Report, based on the so-called Representative Concentration Pathways (RCP) by which climate is a function of radiative forcing $\left(\mathrm{W} / \mathrm{m}^{2}\right)$ rather than GHG emissions directly (van Vuuren et al. 2011), specifically RCP $4.5\left(4.5 \mathrm{~W} / \mathrm{m}^{2}\right.$, medium-low forcing), RCP $6.0\left(6.0 \mathrm{~W} / \mathrm{m}^{2}\right.$, medium forcing), and RCP $8.5\left(8.5 \mathrm{~W} / \mathrm{m}^{2}\right.$, high forcing). These scenarios are roughly correlative to the IPCC AR4 SRES scenarios B1, A1B, and A2, respectively (van Vuuren et al. 2011; Vavrus et al. 2012). Monthly means of sea ice concentration and thickness from one 21 st-century CCSM4 simulation (termed simulation \#1) were obtained for each RCP scenario, for three 20-year periods representing early-, mid- and late-century conditions (2011-2030, 2046-2065, and 2080-2099), respectively. These 21stcentury simulations were initialized from the same historical 20th-century baseline conditions. Data representing a late-20th-century baseline (1980-1999) were also obtained from this historical simulation. Monthly means were averaged over each 20 -year sample to obtain a single grid for each month at each time window. In order to calculate navigation season length (Section 2.4), daily means were also acquired for summer (July-October) and winter (December-March) from CCSM4 simulation \#6 (simulation \#7 replaces \#6 for RCP 8.5). Daily simulations for each RCP scenario were initialized from the same 20th-century conditions as for monthly means. All grids were projected to a Lambert Azimuthal Equal-Area projection at $5-\mathrm{km}^{2}$ resolution using nearest-neighbor interpolation to allow more precise calculation of accessible area within EEZs and navigation routes.

\subsection{Ship-accessible area}

Methods for calculating ship-accessible area at sea are described in detail in Stephenson et al. (2011), and summarized here (see also Supplementary Methods). 
Whether ships may traverse ice-covered waters safely depends on both the structural and engineering capabilities of the ship and the geophysical properties of the surrounding ice regime. The Arctic Ice Regime Shipping System (AIRSS) provides a framework for assessing whether a ship may navigate safely in ice-covered waters based on its design and the ice conditions present (Transport Canada 1998). The ability of a ship to enter a particular ice regime is given by the Ice Numeral:

$$
I N=\left(C_{a} * I M_{a}\right)+\left(C_{b} * I M_{b}\right)+\ldots+\left(C_{n} * I M_{n}\right)
$$

Where $I N$ is the Ice Numeral, $C_{a} / C_{b}$ is the sea ice concentration in tenths of ice type $a / b$ and $I M_{a} / I M_{b}$ is the Ice Multiplier of ice type $a / b$. A negative Ice Numeral signifies that the ice regime presents a significant hazard to the given vessel. Although passage may be possible in such conditions, the likelihood of accidents has been shown to be considerably higher where the Ice Numeral is negative (Timco et al. 2004). The Ice Multiplier is a nonzero integer variable (ranging from -4 to 2 ) indicating the risk presented by a particular ice type to a given vessel class, with lower Ice Multipliers denoting greater risk.

Because sea ice type/age is not available in CCSM4, type/age was approximated from ice thickness according to AIRSS guidelines and observational data (Stephenson et al. 2011). Six ice types, plus an "open water" class, were identified in AIRSS with accompanying thickness ranges. Thickness ranges for older ice classes (MYI and second-year ice) were calculated from observed thickness and age data (Kwok et al. 2007; Maslanik et al. 2007) (Supplementary Methods).

Three vessel classes were chosen to represent a range of capital investment in icestrengthened capability:

- Polar Class 3 (PC3), an icebreaker capable of "year-round operation in second-year ice which may include multi-year ice inclusions";

- Polar Class 6 (PC6), a moderately ice-strengthened ship capable of "summer/autumn operation in medium first-year ice which may include old ice inclusions";

- Open-water (OW) ships with no ice strengthening (IMO 2002) (see also Supplementary Methods)

Ice Multipliers for PC3, PC6, and OW ships (Table S3) were used to calculate Ice Numeral grids following the AIRSS framework, representing all combinations of the three RCP scenarios, 20-year time windows, and vessel classes. For any given location, ship access for a particular vessel class was deemed feasible if the corresponding Ice Numeral for that class was non-negative. Total accessible area $\left(\mathrm{km}^{2}\right)$ was calculated for the five state EEZs, international high seas (central Arctic Ocean), and three navigation routes described in Section 2.1.

\subsection{Navigation season length}

Previous studies have defined navigation season as the number of days per year with less than a defined threshold of percent ice cover (ACIA 2004a), which ignores other navigationcritical properties of sea ice (particularly thickness) and assumes that all vessels have equal ice capability. In order to calculate marine access in terms of navigation season length for multiple vessel classes, the present methodology was repeated using daily CCSM4 data for two seasonal periods: "summer" (July-October; maximum season length: 123 days) and "winter" (December-March; maximum season length: 121 days). For each forcing scenario and vessel class described above, daily Ice Numeral grids were created for these summer and winter seasons for each year of the 20-year time windows. Yearly "navigation season length" 
grids for summer and winter were created by computing the number of days during the season that each grid cell was accessible to a given vessel class. These yearly grids were then averaged over each 20-year time window to obtain period-mean navigation season length during a season (Fig. 3). Variability in the navigation season was computed by calculating the standard deviation of the navigation season length over each 20 -year period.

\section{Results}

21st-century projections of accessible area (hereafter termed "access") are presented for the aggregate circumpolar region (Section 3.1), disaggregated state EEZs (Canada, Greenland/Denmark, Norway, Russia, U.S.; Supplementary Results) and the international high seas (Supplementary Results). Accessible area is discussed with respect to three vessel classes (PC3, PC6, OW) and three forcing scenarios (RCP 4.5, 6.0, 8.5). In addition, summer navigation season length (i.e. the average number of accessible days between July 1 and October 31 , for a maximum season length of 123 days) and variability (i.e. the standard deviation of season length) are also discussed within each regional unit for the early-century time window (2011-2030) under medium forcing (RCP 6.0) only. Finally, projected navigation season lengths and variability along the NWP, NSR, and TPR navigation routes are provided for all forcing scenarios (Table S2), and discussed in detail for the early-century RCP 6.0 scenario only (Section 3.2). Complete results are provided in Supplementary Material.

\subsection{Aggregate circumpolar totals for the IMO guidelines boundary region}

In all time window and forcing scenarios, PC3 vessels have access to a substantial majority of the IMO Guidelines Boundary region year-round (Fig. 2; Table S1). At baseline (19801999), $54 \%$ of the region is accessible to PC3 vessels on average annually, rising to $75 \%$ / $72 \% / 79 \%$ by early-century (for the RCP 4.5 / 6.0 / 8.5 scenarios, respectively) with $84 \%$ / $82 \% / 87 \%$ accessible during July-October. By mid-century, average annual access rises further to $89 \% / 91 \% / 94 \%$, and by late-century, PC3 vessels gain access to nearly the entire IMO Guidelines Boundary region ( $93 \%$ / $95 \%$ / $98 \%$ ). The rate of this increase is non-linear, with PC3 vessels gaining access more rapidly during the first half of the $21 \mathrm{st}$ century than the latter half (Figure S2). Seasonal fluctuations are somewhat muted (Figure S3A). All mid-century and late-century scenarios suggest access to at least $88 \%$ of the IMO Boundary region year-round to PC3 icebreakers, with a maximum of $99 \%$ (in summer) by late-century. In general, 21 st-century projections for PC3 vessels suggest incremental access gains, especially in the early decades of the century, with a weak seasonal response.

For PC6 vessels, model projections suggest substantial access increases by mid-century (Fig. 2; Table S1). Relative to baseline (36\% annual average), access is still limited at earlycentury (45\% / $44 \%$ / $48 \%$ of IMO Boundary area annual average; $66 \%$ / $64 \%$ / $71 \%$ July-October). By mid-century, however, access is considerably higher in all scenarios (58\% / $61 \%$ / $69 \%$ ) with summer levels approaching those of PC3 vessels (82 \% / $85 \%$ / $91 \%$ July-October). By late-century, the region becomes nearly fully accessible to PC6 vessels in summer (90\% / $93 \%$ / $98 \%$ July-October) and, under the highest climate forcing, maintains high access nearly year-round ( $68 \% / 73 \% / 93 \%)$. Most of these access gains occur in the first half of the 21st century under RCP 4.5 and RCP 6.0, and in the latter half of the century under RCP 8.5 (Figure S2). In contrast to PC3 vessels, PC6 vessels exhibit a strong seasonal pattern marked by substantially higher access in summer than in winter (Figure S3B). Access during July-October is $82 \%$ (average of all projections), compared with $56 \%$ during 
$20^{\text {th }}$-century baseline

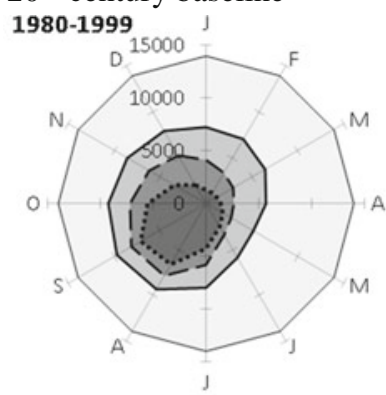

RCP 4.5

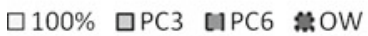
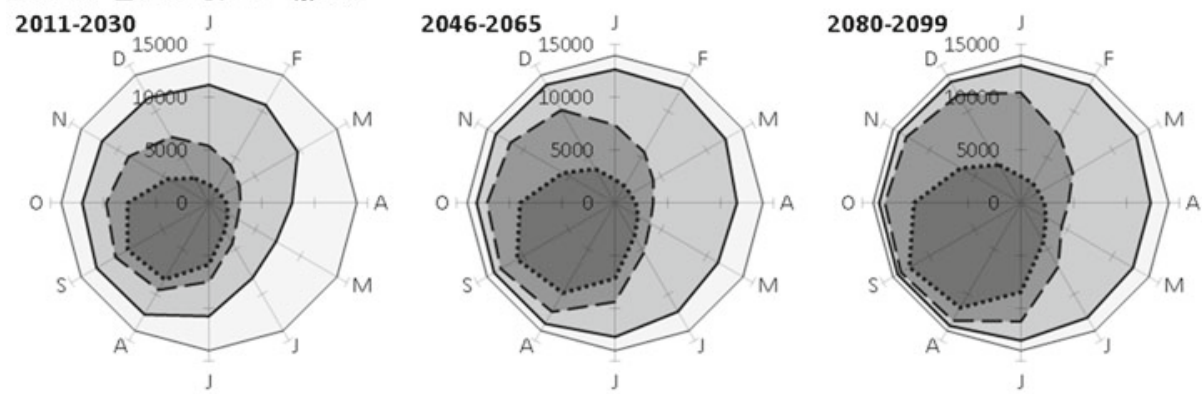

RCP 6.0

\section{$\square 100 \%$ 口PC3 LIPC6}
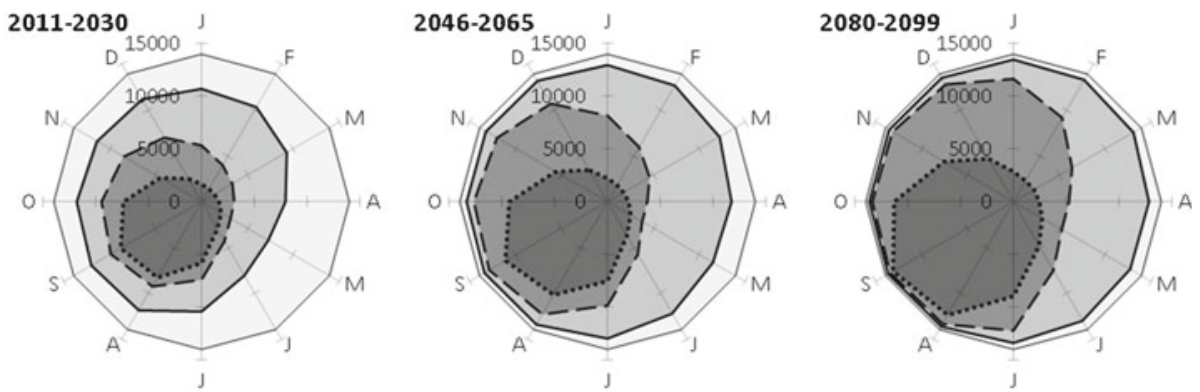

RCP 8.5

\section{$\square 100 \%$ 口PC3 LIPC6 慁OW}
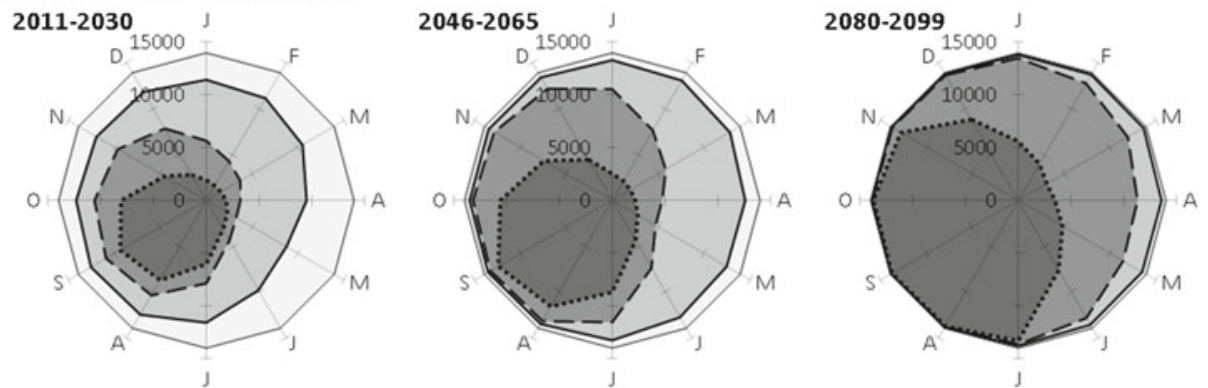

Fig. 2 Total ship-accessible marine area in the aggregate IMO Arctic Ship Guidelines Boundary region $\left(1,000 \mathrm{~km}^{2}\right)$ as driven by climate forcing scenario (RCP 4.5, 6.0, 8.5), time-averaging window (2011-2030, 2046-2065, 2080-2099), and vessel class (PC3, PC6, OW). Outer circles signify 100 \%year-round access. For reference, baseline late-20thcentury historical values (1980-1999) are also shown 
December-March. The RCP 8.5/late-century scenario is markedly more accessible in winter and exhibits less seasonal fluctuation than any other scenario.

OW vessel access is limited in all forcing/time window scenarios and is generally restricted to summer months (Fig. 2; Table S1). At baseline, only $23 \%$ of the IMO region is accessible to these vessels. Average annual access is low at early-century $(29 \% / 29 \% / 31 \%)$ and remains marginal by late-century regardless of assumed climate forcing scenario (41 \% / $45 \%$ / $62 \%)$. By late-century, however, summer access is significantly higher (76 \% / $81 \% / 97 \%$ ) especially under RCP 8.5. Access gains are lower compared to those of PC3 and PC6 vessels and occur mainly in summer (Figure S2). Winter access is low in every scenario and differences due to forcing and time window are minimal, with the exception of the RCP 8.5/late-century scenario which is substantially more accessible than any other throughout the year (Figure S3C). In general, projections for $\mathrm{OW}$ vessels suggest incremental access gains in summer throughout the century, with greater gains under higher forcing scenarios, and very low access in winter under all forcing scenarios. This result underscores a future of limited summer operation of OW vessels throughout the Arctic Ocean.

\subsection{Potential navigation routes}

\subsubsection{The Northwest Passage}

At early-century, navigation season length for PC3 vessels is severely shorter in the Canadian Arctic Archipelago (CAA) than anywhere else along the NWP (Fig. 3). While navigation season averages $\sim 105-120$ days at the eastern mouth of Lancaster Sound,
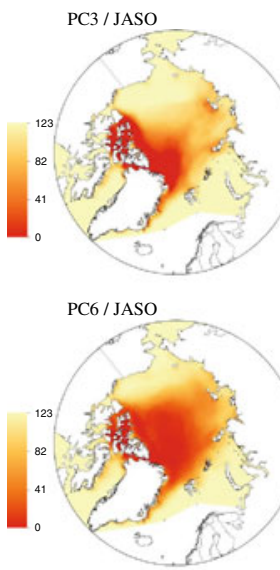

OW / JASO

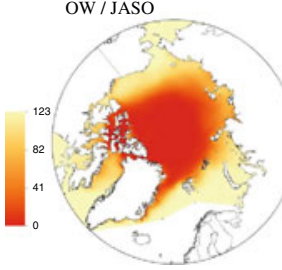

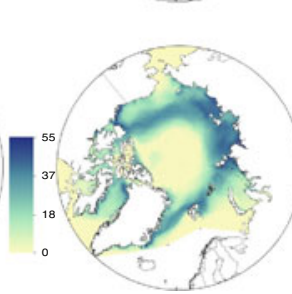
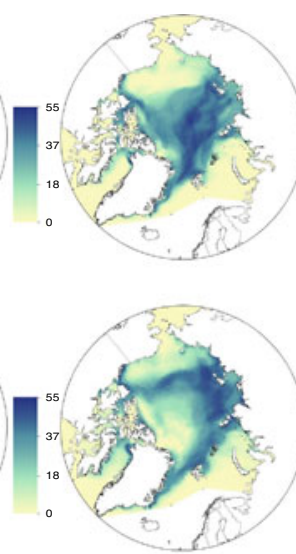
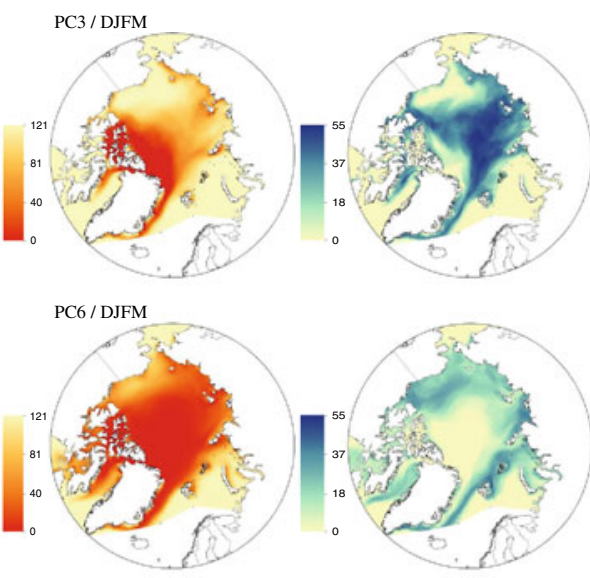

OW / DJFM
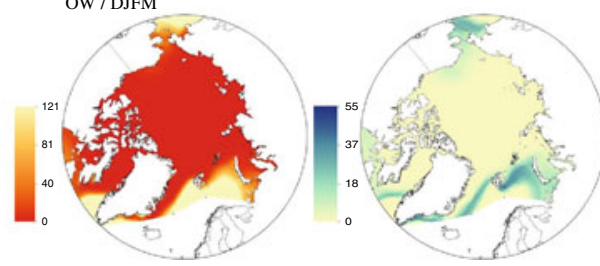

Fig. 3 Number of ship-accessible days in "summer" (July-October, left) and "winter" (December-March, right) for PC3, PC6, and OW vessels (red: average; blue: standard deviation) at early-century (2011-2030) under medium forcing (RCP 6.0) 
pervasive ice to the west, in Parry Channel, limits PC3 vessels to $<15$ operating days. Variability is high at the eastern and western ends of Parry Channel $(\sigma \sim 25-43)$ and lower in the Barrow Strait $(\sigma \sim 0-25)$. Upon exiting the M'Clure Strait, navigation season length increases dramatically (Bering Strait: average $\sim 120$ days; $\sigma \sim 0$ ). Overall, summer navigation season grows by $+20 /+10 /+37$ days by mid-century and $+15 /+20 /+38$ days by latecentury, under RCP 4.5 / 6.0 / 8.5, respectively (Table S2). The surprising finding that fewer days are accessible by late-century than by mid-century could result from continued import of heavy ice from the central Arctic Ocean into Parry Channel (e.g. (Howell et al. 2009)).

PC6 vessels may only navigate for short periods along Parry Channel at early-century. Navigation season length is near zero west of Lancaster Sound, though access may be marginally higher in some sections of Parry Channel (e.g., Viscount Melville Sound, average $\sim 10-30$ days). Variability is relatively high at the eastern $(\sigma \sim 12-40)$ and western $(\sigma \sim 33-37)$ termini of Parry Channel and low in between $(\sigma \sim 0$ Barrow Strait). Navigation season is substantially longer west of the CAA with low to moderate variability (Beaufort Sea: average $\sim 60-120$ days, $\sigma \sim 5-30$; Chukchi Sea: 110-120 days, $\sigma \sim 0-16)$. Overall, summer navigation season grows by $+17 /+9 /+40$ days by mid-century and $+15 /+31 /+45$ days by late-century.

OW vessels may not navigate in the eastern NWP for more than 10 days in summer at earlycentury. Navigation season length is near zero in much of Parry Channel. The western mouth of the M'Clure Strait is the most variable portion of the NWP for OW vessels $(\sigma \sim 30-38)$. Navigation season is relatively long west of the CAA with moderate variability (average $\sim 50$ 120 days, $\sigma \sim 5-25)$. Variability decreases with proximity to the Bering Strait $(\sigma \sim 0)$. Overall, summer navigation season grows by $+14 /+7 /+39$ days by mid-century and $+15 /+28 /+50$ days by late-century. These short periods of navigation for OW ships represent a strong limitation to use of the NWP for trans-Arctic voyages.

\subsubsection{The Northern Sea Route}

Navigation seasons along the NSR are the longest of the Arctic routes examined in this study. At early-century, PC3 vessels may navigate reliably for nearly a full summer (average $>120$ days; $\sigma \sim 0-10$ ) in the western and eastern portions of the NSR (Fig. 3). The central portion of the NSR tends to be highly variable, particularly in the eastern Kara Sea and Vilkitsky Strait (average 95-105 days; $\sigma \sim 40$ ) and north of the New Siberian Islands (average $\sim 70-80$ days; $\sigma \sim 40-45$ ). Overall, summer navigation season grows by $+9 /+7 /+4$ days by mid-century and $+10 /+12 /+5$ days by late-century (Table S2).

PC6 vessels may navigate for relatively long periods in summer along the NSR at earlycentury. Navigation season is longest in the Chukchi (average $\sim 110-120$ days; $\sigma \sim 0-17$ ) and western and central Kara (average $\sim 100-120$ days; $\sigma \sim 3-20$ ) Seas. The route passing through the Laptev Sea (average $\sim 75-90$ days; $\sigma \sim 35-43$ ) and north of the New Siberian Islands (average $\sim 45-60$ days) is especially unreliable $(\sigma \sim 40-50)$. The Vilkitsky Strait is accessible for slightly longer (average $~ 85-90$ days) but is similarly unreliable $(\sigma \sim 45-50)$. Overall, summer navigation season grows by $+15 /+9 /+10$ days by mid-century and $+19 /+21 /+13$ days by late-century.

OW vessel navigation along the NSR at early-century is generally limited to summer in the western and central Kara (average $\sim 90-120$ days) and Chukchi (average $\sim 110-120$ days) Seas. Navigation season is substantially shorter in the Laptev (average $\sim 35-65$ days) and East Siberian (average $\sim 35-100$ days) Seas. Variability is especially high in the Vilkitsky Strait $(\sigma \sim 40-48)$, in the Laptev Sea $(\sigma \sim 40)$, and immediately east of the New Siberian Islands $(\sigma \sim 40)$. Brief, highly variable seasons in these areas suggest that interannual variability will largely determine whether OW vessels may navigate the NSR for any length 
of time at early-century. Overall, summer navigation season grows by $+20 /+12 /+15$ days by mid-century and $+28 /+30 /+24$ days by late-century.

\subsubsection{The Trans-Polar Route}

At early-century, navigation season for PC3 vessels along the TPR is brief and highly variable from the Fram Strait to the North Pole, growing longer and less variable with proximity to the Bering Strait (Fig. 3). While PC3 vessels may navigate in the Fram Strait for over two months in summer (average $\sim 65-80$ days), navigation season shrinks to approximately one month with high variability near the North Pole (average $\sim 25-35$ days; $\sigma \sim 35-$ 45). PC3 vessels may reliably navigate north of the Chukchi Sea to the Bering Strait (average $\sim 115-120$ days; $\sigma \sim 0-4)$. Overall, summer navigation season grows by $+30 /+24 /+24$ days by mid-century and $+31 /+38 /+24$ days by late-century (Table S2).

PC6 vessels may navigate along the TPR only sporadically at early-century. Navigation season length is brief in the Fram Strait (average 10-28 days) and throughout the central Arctic Ocean (average $<30$ days) with low to moderate variability $(\sigma \sim 0-25)$. Navigation season variability increases with proximity to the Bering Strait, reaching a maximum north of the Chukchi Sea $(\sigma \sim 42)$. Overall, summer navigation season grows by $+29 /+25 /+46$ days by mid-century and $+47 /+64 /+61$ days by late-century.

There is virtually no navigation season for OW vessels at early-century along the TPR. Navigation season length is less than 10 days from the Fram Strait to the Chukchi Sea, and reliably near zero throughout much of the central Arctic Ocean (average $\sim 0-3$ days; $\sigma \sim 0$ ). From the Chukchi Sea to the Bering Strait, seasons are markedly longer (average $\sim 100-120$ days) and less variable $(\sigma \sim 0-15)$. Overall, summer navigation season grows by $+9 /+8 /+30$ days by midcentury and $+24 /+37 /+74$ days by late-century.

\section{Discussion}

While ship-accessible area and navigation season length increase in all scenarios and share broadly similar geographic patterns, the choice of forcing scenario is important. In particular, the highest radiative forcing scenario (RCP 8.5) is a significant driver of access change, especially for the weaker vessel classes. By late century, PC6 and OW access is considerably higher for this scenario than either RCP 4.5 or 6.0 (Figure S3 B, C), with the IMO Guidelines Boundary becoming over $90 \%$ accessible to OW vessels from July to November (four months longer than under RCP 6.0). Moreover, PC6 vessels gain access to at least $80 \%$ of the aggregate region in winter (February-June) under RCP 8.5, whereas less than half of the region becomes accessible under RCP 6.0. High forcing also results in large non-linear access gains at the margins of the summer navigation season (July and November) for OW vessels and in winter for PC6 vessels between mid-century and latecentury (Figure S3 B,C). In contrast, access under medium-low forcing (RCP 4.5) is very similar to that under medium forcing (RCP 6.0): by mid-century, aggregate year-round access is no more than $3 \%$ greater under RCP 6.0 than under RCP 4.5 for any vessel class. This result reflects the trajectories described by van Vuuren et al. (2011), which indicate similar radiative forcing for these scenarios (and slightly higher for RCP 4.5) until approximately 2060. These trajectories also explain the finding of greater access in aggregate at early-century (Table $\mathrm{S} 1$ ) and longer average navigation seasons by mid-century (Table S2) under RCP 4.5. However, even by late-century, differences between RCP 4.5 and RCP 6.0 are marginal in aggregate. Viewed collectively, these results suggest a non-linear response of technical ship access to climate forcing, by which access increases sharply under the warmest climate forcing scenario. 
Large disparities in access due to vessel class are evident in all scenarios. It is generally recognized in policy circles that ice-capable ships will continue to be necessary for Arctic navigation in the near term as ice recedes (IMO 2002; Arctic Council 2009). However, recent projections of an ice-free summer before 2050 (Holland et al. 2006; Wang and Overland 2009) may engender the notion that ice-capable ships will diminish in strategic importance. While the results presented here indeed indicate increasing future access for all vessel types (Fig. 2), the differences due to vessel class are striking and often exceed the impacts of climate forcing alone. For example, at mid-century, PC3 vessels have access to the vast majority of the IMO Guidelines Boundary area year-round, whereas for PC6 vessels, January access is less than two-thirds of the September maximum (RCP 6.0). By late-century in winter, the IMO Guidelines Boundary area is fully accessible to PC3 vessels save for the northern CAA and western central Arctic, whereas OW vessels are restricted to portions of the Bering, Barents, Chukchi and Greenland Seas only. In general, PC3 vessels are able to navigate relatively freely in all forcing scenarios with relatively minor seasonal fluctuation, while weaker vessels (especially OW) are comparatively more subject to differences in climate forcing and the intra-annual timing of ice retreat.

Aggregate totals for the IMO Guidelines Boundary region are useful for general summarization but obscure strong geographic variations in projected ship-accessible area and navigation season length (see Supplementary Results). By late-century, the EEZs of Norway and the U.S. are projected to be nearly fully accessible year-round to polar-classed vessels (98\% and $96 \%$ to PC6; $99 \%$ and $100 \%$ to PC3, respectively; three-forcing average), with marginally lower figures for the Russian maritime Arctic (85\% PC6; $99 \%$ PC3). In contrast, access to the Greenlandic EEZ is lower (75 \% PC6; 90 \% PC3), and lower still for the Canadian EEZ (65\% PC6; $87 \%$ PC3). Perhaps the most striking change occurs in the international high seas, where access increases from $4 \%$ (PC6) / $18 \%$ (PC3) in the late 20th century to $73 \%$ (PC6) / $100 \%$ (PC3) by late-century. Of the Arctic Ocean coastal states, Russia (36 \% / $47 \% / 35 \%)$ is projected to gain access to the greatest percentage of its EEZ by late-century (PC3 / PC6 / OW, 3 -forcing average), followed by Greenland/Denmark (34 \% / $33 \% / 22 \%$ ), Norway (27 \% / $32 \%$ / $23 \%$ ), Canada (31 \% / $26 \%$ / $17 \%$ ), and the U.S. (4\% / $24 \% / 27 \%$ ). That all Arctic coastal states stand to gain access to significant portions of previously inaccessible EEZ underscores the pervasive effect of climate change at the circumpolar scale even while absolute access varies widely within the region.

Of the three navigation routes examined here, the NSR is most robustly accessible throughout the 21st century under all forcing scenarios. By mid-century, PC3 and PC6 vessels may access the entire NSR nearly all summer, and OW vessels may navigate for over three months (Table S2). In contrast, the NWP and TPR remain less accessible, especially to weaker vessel types, until the latter half of the century. Note, however, that these findings are spatial averages, and that individual portions of routes may be significantly less accessible and/or more variable than the route average. In most cases, some portions are reliably accessible for a full summer (e.g., Beaufort Sea, Kara Sea) while other portions are accessible only briefly or not at all (e.g., Parry Channel, Laptev Sea). Nevertheless, these results suggest that the NSR remains the most viable option for Arctic navigation in the near term. By late-century, however, the TPR is projected to become viable for polar-classed vessels, suggesting that routing decisions may increasingly be made to maximize distance savings rather than ice avoidance in the long term. Even so, trans-Arctic navigation is likely to remain a summertime phenomenon, as illustrated by stark contrasts in navigation season length (Fig. 3).

Despite our projections of widespread increases in technically accessible marine area, numerous challenges continue to constrain Arctic navigation. One key finding is that voyages in the near term are likely to be unreliable due to highly variable navigation seasons 
in much of the region (Fig. 3). In general, this study finds high interannual variability for all vessel classes where average season length is intermediate, and low variability where average season length is high or low. This finding has important implications for transArctic shipping in particular because most trans-Arctic routes pass through at least one zone of intermediate season length. For example, early-century variability for PC3 vessels is highest in the high seas and central seas of the Russian EEZ that comprise critical portions of the TPR and NSR, respectively. Likewise, navigation seasons for PC6 and OW vessels are most variable in a zone encircling the central Arctic Ocean (Fig. 3), encompassing much of the NSR and extending to the Beaufort and Greenland Seas. Thus, while the NSR may be accessible for limited periods at early-century, its access is unpredictable from year to year for all vessel classes. Ice forecasting and monitoring systems, such as satellite-borne synthetic aperture radar (SAR), may mitigate short-term unpredictability by providing daily to weekly estimates of ice concentration and type characteristics, though such techniques have yet to be implemented extensively throughout the Arctic (Johannessen et al. 2007; Sakov et al. 2012). The NWP is similarly variable along Parry Channel, though its average access is much lower than that of the NSR. The early-century projections of short seasons for all vessel classes in Parry Channel suggest that "choke points" and MYI invasions will continue to pose a hazard along the NWP in the near future (Howell et al. 2009). However, the coarse spatial resolution of CCSM4 $\left(1^{\circ}\right)$ limits the utility of sea ice projections in geographically complex regions such as the CAA; thus, results presented for the Canadian maritime Arctic are less reliable than those of other regions. While the TPR holds limited promise for PC3 vessels in summer at early-century, high variability from the Fram Strait to the pole illustrates the impracticality of the TPR for strategic planning in the near term.

It is important to note that because this study uses one simulation from one model, its results reflect only the scenario-based uncertainty between the RCPs. This study aims to quantify the uncertainty arising from external climate forcing in order to assess the impact of anthropogenic greenhouse gas emissions on marine access. An alternative analysis might also explore variability between models using a multi-model approach, as demonstrated by Khon et al. (2010) who found significant differences among the CMIP3 models in their ability to represent ice season length in the NWP and NSR. As CCSM4 reaches its minimum downward trend in September sea ice extent somewhat later than the mean of CMIP5 models (Massonnet et al. 2012), access might be expected to increase somewhat faster if driven by an ensemble of models. Furthermore, these results may be conservative since ice extent is greater in CCSM4 than the CMIP5 29-model mean through most of the 21st century (Massonnet et al. 2012). Other approaches might investigate intra-model variability by comparing several simulations of the same model initialized from different historical conditions. While inter- and intra-model uncertainty remain important constraints on attempts to visualize plausible Arctic futures, forcing scenario-based uncertainty represents a compelling starting point from which to study human impacts on the Arctic environment owing to its strong policy relevance. Future studies might combine this emphasis on human impacts with the multi-model approach of Khon et. al to further refine projections of future Arctic marine access.

\section{Conclusion}

Based on CCSM4-projected trends in sea ice concentration and thickness, this study projects robust, widespread increases in Arctic marine access during summer (July-October) for a range of vessel classes. The two polar-classed vessels examined here (PC3 and PC6) gain technical access to up to $96 \%$ (PC3) and $91 \%$ (PC6) of the aggregate IMO Guidelines Boundary region 
in summer by the middle of this century, rising to $98 \%$ and $98 \%$, respectively by late-century, under the highest radiative forcing scenario $\left(8.5 \mathrm{~W} / \mathrm{m}^{2}\right)$. Even for the lowest forcing scenario $\left(4.5 \mathrm{~W} / \mathrm{m}^{2}\right)$, we estimate $93 \%$ and $82 \%$ summer access by mid-century, and $95 \%$ and $90 \%$ by late-century, respectively. These circumpolar averages mask strong regional contrasts, in which these overall trends are manifested differently within the exclusive economic zones of Canada, Greenland/Denmark, Norway, Russia and the U.S.; the high seas; and the NWP, NSR, and TPR. In general, Russia, Greenland/Denmark, and Norway should experience the greatest increases in marine access, and Canada and the U.S. should experience the least owing to continued persistence of ice in the CAA and relatively high access in the U.S. EEZ today. Furthermore, these results are very likely conservative, owing to overestimation of sea ice extent in CCSM4 relative to other CMIP5 models (Massonnet et al. 2012). However, it is important to realize that in the near term, access will be mainly confined to summer months only. The Arctic marine environment is likely to be fully or partially ice-covered 6-8 months each year for the first half of the century, and no climate model projects an ice-free Arctic in winter by 2100 (ACIA 2004a; Stroeve et al. 2012a).

This study represents a first attempt to project future access to the Arctic marine environment for a spectrum of vessel classes and climate change scenarios. For the near future, polar classed ships will remain more important for Arctic operations than open-water ships. Ongoing projections should assist national governments, regulatory and environmental agencies, and the global maritime industry in strategic planning efforts to better understand the range of plausible futures for Arctic marine operations. Furthermore, this work illustrates the usefulness of merging climate model simulations with future Arctic marine regulatory frameworks (i.e. Polar Class vessels as defined by the IMO) to enhance the policy relevance of climate science. While marine access is projected to increase for all climate scenarios, a wide range of futures is possible, and technology (i.e. vessel class) figures importantly - often more importantly - than climatic forcing scenario alone. Therefore, a central conclusion is that Arctic marine access depends strongly upon capital investment and infrastructure in addition to geophysical considerations of sea ice. In this sense, it is a unifying, interdisciplinary concept determined by both the physical environment and human socioeconomic systems.

Acknowledgments This work was supported by the National Science Foundation Graduate Research Fellowship Program (DGE-0707424) and the NASA Cryosphere Program. The authors thank J. Maslanik (University of Colorado, Boulder) for assistance with ice age data; R. MacDonald (Transport Canada) for correspondence regarding shipping in Arctic Canada; François Massonnet (Université Catholique de Louvain) for background on sea ice modeling; M. Zebrowski (UCLA) for figure formatting; and D. Rigby, Y. Sheng, V. Chu, C. Gleason, E. Lyons, M. Mersel, J. Wang (UCLA), and two anonymous reviewers for thoughtful comments on previous versions of this manuscript.

Open Access This article is distributed under the terms of the Creative Commons Attribution License which permits any use, distribution, and reproduction in any medium, provided the original author(s) and the source are credited.

\section{References}

ACIA (2004a) Arctic climate impact assessment: infrastructure: buildings, support systems, and industrial facilities. Arctic Council

ACIA (2004b) Arctic climate impact assessment: cryosphere and hydrology. Arctic Council

Arctic Council (2009) Arctic marine shipping assessment 2009 report

Astill J (2012) The melting north. The Economist. June 16

Barents Observer (2011a) Rosneft picks ExxonMobil in Arctic deal (September 1) 
Barents Observer (2011b) First supertanker along Northern Sea Route (August 24)

Barents Observer (2011c) Speed record on Northern Sea Route (August 17)

Boe A et al (2009) September sea-ice cover in the Arctic Ocean projected to vanish by 2100. Nat Geosci 2:341-343

Christensen JH et al (2007) Regional climate projections. Climate change 2007: the physical science basis. Contribution of working group I to the fourth assessment report of the intergovernmental panel on climate change. Cambridge University Press, Cambridge

Comiso JC (2012) Large decadal decline of the Arctic multiyear ice cover. J Climate 25:1176-1193

Comiso JC et al (2008) Accelerated decline in the Arctic sea ice cover. Geophys Res Lett 35:L01703. doi:10.1029/2007GL031972

Day JJ et al (2012) Sources of multi-decadal variability in Arctic sea ice extent. Environ Res Lett 7. doi:10.1088/1748-9326/7/3/034011

Holland MM et al (2006) Future abrupt reductions in the summer Arctic sea ice. Geophys Res Lett 33:L23503

Howell S et al (2009) Sea ice conditions and melt season duration variability within the Canadian Arctic Archipelago: 1979-2008. Geophys Res Lett 36:L10502. doi:10.1029/2009GL037681

IMO (2002) Guidelines for ships operating in Arctic ice-covered waters. MSC/Circ.1056 and MEPC/Circ.399

Johannessen OM et al (2007) Remote sensing of sea ice in the Northern Sea Route. Springer, Chichester

Kattsov VM et al (2010) Arctic sea-ice change: a grand challenge of climate science. J Glaciol 56:1115-1121

Kay JE et al (2011) Inter-annual to multi-decadal Arctic sea ice extent trends in a warming world. Geophys Res Lett 38:L15708. doi:10.1029/2011GL048008

Khon VC et al (2010) Perspectives of Northern Sea Route and Northwest Passage in the twenty-first century. Clim Chang 100:757-768

Kinnard C et al (2011) Reconstructed changes in Arctic sea ice over the past 1450 years. Nature 479:509-512

Kwok R et al (2007) Ice, Cloud, and land Elevation Satellite (ICESat) over Arctic sea ice: retrieval of freeboard. J Geophys Res 112:C12013. doi:10.1029/2006JC003978

Kwok R et al (2009) Thinning and volume loss of the Arctic Ocean sea ice cover: 2003-2008. J Geophys Res 114:C07005

Liu M, Kronbak J (2010) The potential economic viability of using the Northern Sea Route (NSR) as an alternative route between Asia and Europe. J Transp Geogr 18:434-444

Maslanik JA et al (2007) A younger, thinner Arctic ice cover: increased potential for rapid, extensive sea-ice loss. Geophys Res Lett 34:L24501. doi:10.1029/2007GL032043

Maslanik J et al (2011) Distribution and trends in Arctic sea ice age through spring 2011. Geophys Res Lett 38:L13502. doi:10.1029/2011GL047735

Massonnet F et al (2012) Constraining projections of summer Arctic sea ice. Cryosphere 6:1383-1394

NCAR (2012) Community climate system model 4.0

Notz D, Marotzke J (2012) Observations reveal external driver for Arctic sea-ice retreat. Geophys Res Lett. doi:10.1029/2012GL051094

NSIDC (2012) Arctic sea ice maximum marks beginning of melt season

Paxian A et al (2010) Present-day and future global bottom-up ship emission inventories including polar routes. Environ Sci Technol 44:1333-1339

Peters GP et al (2011) Future emissions from shipping and petroleum activities in the Arctic. Atmos Chem Phys 11:5305-5320

Polyakov IV et al (2012) Recent changes of Arctic multiyear sea ice coverage and the likely causes. Bull Am Meteorol Soc. doi:10.1175/BAMS-D-11-00070.1

Potts T, Schofield C (2008) Current legal developments: the Arctic. Int J Mar Coast Law 23:151-176

Rampal P et al (2011) IPCC climate models do not capture Arctic sea ice drift acceleration: consequences in terms of projected sea ice thinning and decline. J Geophys Res 116:C00D07

Sakov P et al (2012) TOPAZ4: an ocean-sea ice data assimilation system for the North Atlantic and Arctic. Ocean Sci 8:633-656

Serreze MC et al (2007) Perspectives on the Arctic's shrinking sea-ice cover. Science 315:1533-1536

Somanathan S et al (2007) Feasibility of a sea route through the Canadian Arctic. Marit Econ Logist 9:324334

Somanathan S et al (2009) The Northwest Passage: a simulation. Transp Res A 43:127-135

Stephenson SR et al (2011) Divergent long-term trajectories of human access to the Arctic. Nat Clim Chang 1:156-160 Stroeve JC et al (2008) Arctic sea ice extent plummets in 2007. Eos Trans Am Geophys Union 89:13-20

Stroeve JC et al (2012a) The Arctic's rapidly shrinking sea ice cover: a research synthesis. Clim Chang 110:1005-1027

Stroeve JC et al (2012b) Trends in Arctic sea ice extent from CMIP5, CMIP3 and observations. Geophys Res Lett 39: L16502 
Timco G et al (2004) Scientific basis for ice regime system: final report. Transport Canada Transport Canada (1998) Arctic ice regime shipping system (AIRSS) standards

van Vuuren DP et al (2011) The representative concentration pathways: an overview. Clim Chang 109:5-31 Vavrus SJ et al (2012) Twenty-first-century Arctic climate change in CCSM4. J Climate 25:2696-2710

Wang M, Overland JE (2009) A sea ice free summer Arctic within 30 years? Geophys Res Lett 36:L07502 Zhang X, Walsh JE (2006) Toward a seasonally ice-covered Arctic Ocean: scenarios from the IPCC AR4 model simulations. J Climate 19:1730-1747 